\title{
COMPLETE CONSISTENCY AND CONVERGENCE RATE OF THE NEAREST NEIGHBOR ESTIMATOR OF THE DENSITY FUNCTION BASED ON WOD SAMPLES
}

\author{
KAn Chen* , Xufei TANG And JiAngfeng HaO
}

\begin{abstract}
By using the exponential inequality of widely orthant dependent (WOD, for short) random variables, we mainly investigate the complete consistency and convergence rate of the nearest neighbor estimator of the density function based on WOD samples. The results obtained in the paper generalize and improve some corresponding ones in the literature. In addition, the restriction on the dominating coefficients $g(n)$ is much weak, even if the geometric growth of $g(n)$, the consistency result and convergence rate still hold by using the results that we obtained.
\end{abstract}

Mathematics subject classification (2010): 62G05.

Keywords and phrases: WOD samples, nearest neighbor estimator, complete consistency, convergence rate.

\section{REFERENCES}

[1] D. O. Loftsgarden, C. P. Quesenberry, A nonparametric estimate of a multivariate density function, The Annals of Mathematical Statistics, 36 (3), 1049-1051, 1965.

[2] T. J. WAGNER, Strong consistency of a nonparametric estimate of a density function, IEEE Transactions on Systems, Man, and Cybernetics, 3, 289-290, 1973.

[3] D. S. Moore, E. G. HenriChon, Uniform consistency of some estimates of a density function, The Annals of Mathematical Statistics, 40 (4), 1499-1502, 1969.

[4] L. P. DEVROYE, T. J. WAGNER, The strong uniform consistency of nearest neighbor density estimates, The Annals of Statistics, 5, 536-540, 1977.

[5] X. R. CHEN, The rate of consistency of nearest neighbor density estimator, Science in China Series A: Mathematics, 12, 1419-1428, 1981.

[6] G. Boente, R. Fraiman, Consistency of a nonparametric estimate of a density function for dependent variables, Journal of Multivariate Analysis, 25 (1), 90-99, 1988.

[7] G. X. CHAI, Consistency of nearest neighbor density estimator of stationary processes, Acta Mathematica Sinica, 32 (3), 423-432, 1989.

[8] Y. LIU, Y. ZHANG, The consistency and asymptotic normality of nearest neighbor density estimator under $\varphi$-mixing condition, Acta Mathematica Sinica, 30 (3), 733-738, 2010.

[9] S. C. YANG, Consistency of nearest neighbor estimator of density function for negative associated samples, Acta Mathematicae Applicatae Sinica, 26 (3), 385-395, 2003.

[10] X. J. WANG, H. S. Hu, The consistency of the nearest neighbor estimator of the density function based on WOD samples, Journal of Mathematical Analysis and Applications, 429 (1), 497-512, 2015.

[11] K. Y. WANG, Y. B. WANG, Q. W. GAO, Uniform asymptotics for the finite-time ruin probability of a new dependent risk model with a constant interest rate, Methodology and Computing in Applied Probability, 15, 109-124, 2013.

[12] L. LiU, Precise large deviations for dependent random variables with heavy tails, Statistics and Probability Letters, 79, 1290-1298, 2009.

[13] E. L. Lehmann, Some concepts of dependence, The Annals of Mathematical Statistics, 37, 1137$1153,1966$. 
[14] K. JoAg-Dev, F. Proschan, Negative association of random variables with applications, The Annals of Statistics, 11, 286-295, 1983.

[15] T. Z. HU, Negatively superadditive dependence of random variables with applications, Chinese Journal of Applied Probability and Statistics, 16, 133-144, 2000.

[16] Y. WANG, D. CHENG, Basic renewal theorems for random walks with widely dependent increments, Journal of Mathematical Analysis and Applications, 384, 597-606, 2011.

[17] Y. WANG, Z. CUI, K. WANG, X. MA, Uniform asymptotics of the finite-time ruin probability for all times, Journal of Mathematical Analysis and Applications, 390, 208-223, 2012.

[18] A. T. SHEN, Bernstein-type inequality for widely dependent sequence and its application to nonparametric regression models, Abstract and Applied Analysis, volume 2013, Article ID 862602, 9 pages, 2013.

[19] A. T. SHEN, On asymptotic approximation of inverse moments for a class of nonnegative random variables, Statistics: A Journal of Theoretical and Applied Statistics, 48 (6), 1371-1379, 2014.

[20] W. He, D. CHENG, Y. WANG, Asymptotic lower bounds of precise large deviations with nonnegative and dependent random variables, Statistics and Probability Letters, 83, 331-338, 2013.

[21] X. J. WAnG, C. XU, T.-C. Hu, A. Volodin, S. H. Hu, On complete convergence for widely orthant-dependent random variables and its applications in nonparametric regression models, TEST, 23, 607-629, 2014.

[22] W. Z. YANG, T. T. LIU, X. J. WANG, S. H. HU, On the Bahadur representation of sample quantiles for widely orthant dependent sequences, Filomat, 28, 1333-1343, 2014.

[23] Y. Wu, X. J. WANG, T.-C. HU, M. O. CABRERA, A. Volodin, Limiting behaviour for arrays of rowwise widely orthant dependent random variables under conditions of $R$ - $h$-integrability and its applications, Stochastics, 91 (6), 916-944, 2019.

[24] P. Y. Chen, S. H. Sung, A Spitzer-type law of large numbers for widely orthant dependent random variables, Statistics \& Probability Letters, 154, 2019, Article ID 108544, https://doi.org/10.1016/j.spl.2019.06.020.

[25] A. T. SHEN, C. Q. Wu, Complete q-th moment convergence and its statistical applications, RACSAM, 114, 2020, Article ID 35, https://doi .org/10.1007/s13398-019-00778-2.

[26] H. XIA, Y. WU, X. R. TAO, X. J. WANG, The consistency for the weighted estimator of nonparametric regression model based on widely orthant dependent errors, Probability in the Engineering and Informational Sciences, 32 (3), 469-481, 2018. 